\title{
Resistance pattern and maternal knowledge, attitude and practices of suspected Diarrheagenic Escherichia coli among children under 5 years of age in Addis Ababa, Ethiopia: cross sectional study
}

Yeshwondm Mamuye GebreSilasie ${ }^{1}$, Kassu Desta Tullu² and Addisu Gize Yeshanew ${ }^{1 *}$

\begin{abstract}
Background: Diarrheal illness remains one of the leading causes of morbidity and mortality among children under 5 years of age worldwide, especially in developing countries. Diarrheagenic Escherichia coli (DEC) is the major cause of gastroenteritis in children in the developing world and is associated with high resistance levels to antibiotics. The aims of this study were to isolate and determine susceptibility patterns of DEC among children under 5 years of age with acute diarrhea and to assess maternal knowledge, attitude and practice towards childhood diarrhea.

Methods: A cross sectional study was conducted from August-December 2015 at 3 selected health institutions. Stool samples were cultured and isolated $E$. coli species were run for antimicrobial susceptibility testing using disk diffusion method. In addition, children's caretakers were interviewed using structured questionnaires including a Knowledge, Attitude and Practice (KAPs) survey. Bivariate and multivariate logistic regression analysis was used to quantify the effect of different risk factors on bacterial related diarrhea.

Results: A total of 253 children, 115 males and 138 females with acute diarrhea were enrolled. E. coli was identified in a total of sixty-one children (24.1\%), followed by Shigella (9.1\%) and Salmonella (3.95\%). Additionally, eighty-six children (34.0\%) had parasites identified in stool samples. E. coli isolates showed $83.6 \%$ resistance to ampicillin and augmentin followed by, trimethoprim-sulfamethoxazole (62.3\%). Multiple resistances were observed in $72.1 \%$ of isolates; however, more than $90 \%$ of the strains were sensitive to ciprofloxacin and ceftriaxone. Caretakers identified the following as causes of infection: contaminated food and water (83.4\%), microorganisms (55.3\%), inadequate breast milk (54.1\%), teething (45.1\%), house flies (43.1\%) and evil eye (15.8\%). No hand washing before meals and low levels of knowledge had a significant association with $E$. coli infection $(p<0.05)$.

Conclusion: In children with suspected diarrheagenic E. coli, we observed a high frequency of multidrug resistant $E$. coli. Furthermore, study subjects with low awareness about source, cause and symptoms of the disease were more likely to acquire suspected diarrheagenic $E$. coli infections. Thus, there is a need for more education in addition to continuous surveillance of the prevalence and antibiotic susceptibility pattern of diarrheal bacterial isolates in hospitals and in the community.
\end{abstract}

Keywords: Resistance patterns, Suspected diarrheagenic E. coli, KAPs

\footnotetext{
* Correspondence: konjoaddisu@gmail.com; addisu.gize@sphmmc.edu.et 'Department of Microbiology, St. Paul's Hospital Millennium Medical College, P.O.Box 1271, Addis Ababa, Ethiopia

Full list of author information is available at the end of the article
}

(c) The Author(s). 2018 Open Access This article is distributed under the terms of the Creative Commons Attribution 4.0 International License (http://creativecommons.org/licenses/by/4.0/), which permits unrestricted use, distribution, and reproduction in any medium, provided you give appropriate credit to the original author(s) and the source, provide a link to the Creative Commons license, and indicate if changes were made. The Creative Commons Public Domain Dedication waiver (http://creativecommons.org/publicdomain/zero/1.0/) applies to the data made available in this article, unless otherwise stated. 


\section{Background}

Diarrhea is the third most common cause of deaths among children in sub-Saharan Africa and one of the main causes of hospital admissions in rural areas [1]. It is still considered one of the foremost causes of death in children, accounting for approximately 2 million deaths each year worldwide $[2,3]$. In developing countries like Ethiopia, diarrheal diseases are major causes of infant and child mortality and morbidity [4].

Syndromes of diarrhea can be caused by bacterial, viral and parasitic infections of either single or multiple etiologic agents [5]. Suspected Diarrheagenic Escherichia coli (DEC) are considered to be the most common of the many recognized enteropathogenic organisms, particularly in developing countries and in diarrhea-associated deaths in children under five [6].

Moreover, the emergence of antimicrobial-drug resistance, including resistance to the new and potent antimicrobial agents, is a major public health concern especially in resource-limited countries, like Ethiopia, where bacterial infections are still among the major causes of death, especially for children, it is of particular concern $[7,8]$.

Anti-diarrheal, anti-amoebic and anti-bacterial medications have little role in the management of diarrhea, on the basis of WHO guidelines [9]. However, timely management of the children with fluids resuscitation has substantially declined the mortality and morbidity from acute infectious diarrhea [3]. In Ethiopia, evidence is lacking regarding maternal care-taking and environmental risk factors that contribute to acute diarrhea and the case management of diarrhea. Thus, in view of increasing diarrheal disease and emergence of antimicrobial resistance internationally, there is a need identify misconceptions or misunderstandings about transmission of diarrheal illness in the community in addition to determining resistance patterns of isolated bacterial pathogens involved in diarrheal illness. A Knowledge, Attitude and Practices (KAP) survey is a quantitative method that provides access to quantitative and qualitative information used in multiple studies to understand gaps in knowledge. Therefore, this study provides important input on the emergence of antimicrobial resistance and maternal KAPs to design appropriate control measures for Ethiopian children. This study also will improve awareness to clinicians and local communities in terms of potential targets for intervention strategies.

\section{Methods}

\section{Study area and population}

The study was conducted at outpatient pediatric departments of selected health institutions (Selam health center, Addis Ketema health center, and St. Paul's Hospital Millennium Medical College) in Addis Ababa, Ethiopia from August-December 2015. Addis Ababa is the capital and largest city of Ethiopia. Addis Ababa had an estimated population of 3,384,569 according to the 2007 population census, with annual growth rate of $3.8 \%$. These numbers were initially underestimated, as such; there are no accurate demographic data on Addis Ababa. However, more than $10 \%$ of the Ethiopian population can be attributed to children under five years of age.

\section{Sample size and sampling procedures}

The sample size for the study was calculated using the formula $(n=(z \alpha / 2) 2 \mathrm{p}(1-\mathrm{p}) / \mathrm{d} 2)$ for estimating a single population proportion at $95 \%$ confidence interval (CI) $(\mathrm{Z} \alpha / 2=1.96), 5 \%$ margin of error. Therefore, based on previous prevalence of $E$. coli, $20.8 \%$ study in other health facilities, the total sample size is 253 [10]. This sample size was also applied for caretakers to investigate their KAP. To get those study subjects, we utilized a randomly sampling techniques in which patients from the 3 selected heatlh institutes were our sampling frame (the population from which the samples were chosen). Specifically, we reviewed the daily data about patient flow from the selected health institutions to get the total of $n=253$ subjects or to achieve our total sample size. Consequently, if an average daily patient flow to the pediatric department was $=30$, then our sampling fraction become $(253 / 30=8.4)$ that means almost 8 . Then we selected random number from between 1 and 8 , for example if that number is 3 , the 1 st selected study individual will be 3 , then the 2 nd will be $(3+8=11)$, then the 3 rd will be $(11+$ $8=19$, then the 4 th one will be $(19+8=27) \ldots$. , will continue the pattern of sequence by jumping 8 individuals until the selected participants will become total of 253 study subjects $(3,11,19,27,35,43,51,59,67,75,83$, etc., will be selected individual for the study until the sum of all selected individuals equaled 253 subjects).

\section{Data collection \\ Stool sample collection}

We followed the same study protocol as previously published work for resistance patterns of Shigella and Salmonella spp among under 5 children with acute diarrhea [11]. Trained nurses used a pretested questionnaire to first interview the mother or primary caretaker. The mother or primary caretaker was then given a clean plastic stool container and oriented about sample collection. Once collected, protozoa parasites were identified through direct microscopy using a saline wet mount at each study sites by experienced laboratory technicians/technologists. Part of the stool was kept in Cary-Blair transport media, and transported in an icebox to the microbiology department of St. Paul's Hospital Millennium Medical College (SPHMMC) for further microbiological investigations. 


\section{Culture identification and antimicrobial drug susceptibility test methods}

Enteric pathogen underwent overnight incubation with Selenite-F Broth enrichment media for further multiplication. This was then subsequently sub-cultured onto MacConkey agar (MAC), Salmonella-Shigella agar (SSA) and Deoxycholate citrate agar (DCA), and then incubated aerobically at $37^{\circ} \mathrm{C}$ for $24 \mathrm{~h}$. After overnight incubation, colonies that exhibited characteristics of Salmonella and Shigella species were identified by conventional biochemical methods [12]. Because of many enteric bacteria can also grow in the enrichment broth, further detection techniques were performed to ensure specific isolation of E. coli colonies. Suspicious colonies were transferred to Triple Sugar Iron (TSI) agar, tryptone broth, arabinose broth, and urea broth and incubated for $20 \mathrm{~h}$ at $35^{\circ} \mathrm{C}$. Then $\mathrm{H}_{2} \mathrm{~S}$-positive, urease-positive, arabinose non-fermenting and indole-negative strains were rejected. Both E. coli and Shigella are anaerogenic (i.e. produce little or no gas) and non-motile, therefore to differentiate E. coli from Shigella, slow lactose fermenters were examined for lysine decarboxylase, mucate, and acetate reactions. Shigella sonnei was characterized based on a negative indole reaction and slow or non-fermentation of lactose $[12,13]$.

Shortly, colonies were first examined for lactose fermentation on MacConkey agar. The oxidase and indole tests were performed from a companion blood agar plate. $E$. coli strains were identified as lactose fermenting, betaglucuronidase and indole positive, and oxidase negative. Once suspected diarrheagenic $E$. coli and other enteric bacteria were isolated, drug susceptibility testing was performed using disc diffusion method. Susceptibility testing for all isolates was done and interpreted on the basis of CLSI guidelines [12]. Quality control was performed to check the quality of the medium, the potency of the antibiotic, and assay setup errors. Each new lot was quality controlled before use by testing the E. coli ATCC 25922 standard strains as we describe it previously [11-14].

\section{Maternal knowledge, attitude and practices}

A structured questionnaire was designed to collect information regarding socio-demographics and KAP of the study participants about diarrhea. The questionnaire was first developed in English and translated into Amharic (the local language), and then pre-tested in non-selected health institutions via pilot study for assessing content validity, appropriateness, and question comprehensibility. Then, the questionnaire was revised when necessary. A total of three nurses, one from each selected study area were selected to collect data. Training was given to the data collectors for two days on how to conduct the interview, content of the questionnaire, data quality, and ways to approach respondents. The first author checked the questionnaires for completeness every day. Incomplete questionnaires were returned to data collectors for correction by revisiting the caretakers. Five percent of the interviewed caretakers were randomly selected and re-interviewed by the first author. The KAP survey contains a total of 33 items. Thirteen items were knowledge related questions. Each correct response was assigned score 1 and wrong response was assigned 0 (zero). Thus for 13 items, the maximum attainable score was 13 and minimum was 0 . Nine rating-scale items were for measuring the attitude of caretaker towards childhood diarrhea. The positive items were scored as $1=$ strongly disagree, $2=$ disagree, $3=$ neutral, $4=$ agree, and $5=$ strongly agree. Scoring was reversed for negative items. Eleven items were for measuring the practice of the mother.

\section{Operational definition}

Suspected diarrheagenic E. coli (DEC) in this study was defined as a strain of $E$. coli spp. isolated from children under five years with acute diarrhea and considered as pathogenic.

Diarrhea was defined as at least three loose stools in $24 \mathrm{~h}$ including at least one of nausea, vomiting, abdominal cramps or fever symptoms.

The level of Knowledge, Attitude and Practices was classified according to the following: a poor knowledge corresponded to a score below 50\%, and good knowledge referred to a score $\geq 50 \%$. A score $\geq 50 \%$ was a "positive level" and a score of $<50 \%$ was classified as "negative level" of attitude of caretakers toward childhood diarrhea. A score $<50 \%$ was "poor" and a score $\geq$ $50 \%$ was considered as "good" level of practice.

\section{Data analysis}

Data were double entered, cross-checked using Epi-data version 3.3, and analyzed using SPSS version 20. Enteric bacteria prevalence was determined by dividing the number of individuals infected with enteric bacteria by the total number of individuals examined for bacterial infection. Frequency distribution tables were used to quantify enteric bacterial and parasitic infection, in addition to knowledge of respondents related to sign symptoms, causes, transmission, prevention and control measures of diarrhea. Logistic regression was used to examine the association between independent predictors and dependent enteric bacterial infection. Bivariate and multivariate logistic regression analysis was used to quantify the effect of different risk factors including KAP on bacterial related diarrhea. Values were considered statistically significant at $p<0.05$.

\section{Ethical considerations}

The study obtained ethical clearance from the Department Research and Ethical Review Committee (DRERC) of Addis Ababa University School of Allied Health Sciences, Department of Medical Laboratory sciences and each of 
the selected health institutes. Written informed consent was obtained from voluntary participants and parents or primary caretakers for children during data collection. Individuals who were found positive for bacteria and parasite were treated as per the national guidelines.

\section{Results}

\section{Socio-demographic characteristics of children and} prevalence of diarrhea

As mentioned, this is a part of work from the previous published study [11]. A total of 253 primary caretakers were interviewed and provided stool samples from children for enteric bacterial and parasite identification. The mean age of the patients was 2.61 years with standard deviation (SD) of 1.26 years. In regards to caretakers, most of respondents $(87 \%)$ were females $(n=220)$. For all respondents, $66.0 \%$ were between 26 and 40 years, ranging from 16 to 52 years with a median of 29 years; $86.2 \%$ were married $(n=218)$, and $64.9 \%$ had completed a primary education $(n=164)$. The majority of caretakers (53.4\%) were house wives $(n=135)$; and the income for $47 \%$ of caretaker's $(n=119)$ was less than 500 ETB (18 USD) per month. $5.5 \%$ of the caretakers had completed secondary or a higher level of education (Table 1).

Enteric bacteria were isolated from $94(37.2 \%)$ of the children tested. The predominant isolated organisms were suspected diarrheagenic E. coli spp. $(n=64$ or $24.1 \%$ ), followed by Salmonella species ( $n=23$ or $9.1 \%$ ) and Shigella species $(n=10$ or $3.95 \%)$. $34 \%$ of samples $(n=86)$ were positive for parasites; the most frequently identified protozoan parasites were $E$. histolytica/dispar $(n=45$ or $17.8 \%)$, followed by G. lambia $(n=26$ or $10.3 \%), H$. nana ( $n=9$ or $3.6 \%)$, A. lumbricoides ( $n=5$ or $2.0 \%$ ) and S. stercolaris ( $n=1$ or $0.4 \%$ ).

\section{Antimicrobial sensitivity results of isolates}

The antimicrobial susceptibility testing was done for all suspected diarrheagenic $E$. coli isolates using disk diffusion method. Zones of inhibition were measured by using caliper meter and interpreted as sensitive (S), intermediate (I), and resistance $(\mathrm{R})$ respectively on the basis of CLSI guide lines [14].

Suspected diarrheagenic E. coli (DEC) were isolated from $24.1 \%$ of stool samples. Among patients who had suspected diarrheagenic E. coli infections, the resistance rates were high for ampicillin (83.6\%), augmentin (83.6\%), trimethoprim-sulfamethoxazole (62.3\%), and medium for chloramphenicol (21.3\%), nalidixic acid (19.7\%), and gentamicin (11.5\%). Low levels of resistance were observed against ciprofloxacin (4.9\%) and ceftriaxone (3.3\%) (Table 2).

Antimicrobial resistance to one or more antibiotics was very high among the suspected diarrheagenic E. coli species isolated in the study (83.6\%). Multiple resistances (resistance for two or more commonly used antibiotics) were observed in $85.2 \%$ of the DEC species isolated. One of the isolated strains of suspected diarrheagenic E. coli was resistant for seven antibiotics. Furthermore, susceptibility to all eight antibiotics tested was observed for 3 $(4.9 \%)$ of the isolates.

Knowledge, attitude and practice (KAP) towards diarrhea Out of 253 respondents, $83.4 \%(n=211)$ had heard of diarrhea, and $70.8 \%(n=179)$ of them mentioned diarrhea as one of the major health problems of the community. $97.9 \%$ of caretakers $(n=247)$ used pipe water as the primary source of water in home. However, two patients used stagnant water sources and both were positive for enteric pathogens. On bivariate analysis, low income, $<500$ ETB $(\mathrm{OR}=3.77,95 \% \mathrm{CI}=$ 1.454-9.77, $P$-value $=0.006), \quad 500-1000 \quad$ ETB $\quad(\mathrm{OR}=$ 6.47, 95\% CI $=1.922-21.775, P$-value $=0.003)$ and $a b-$ sence of hand washing before and after meal $(\mathrm{OR}=$ $0.12,95 \% \mathrm{CI}=0.02-0.062, \quad P$-value $=0.03)$ were $\mathrm{im}$ portant independent predictors of suspected diarrheagenic E. coli infections. However, multivariate logistic analysis revealed that only poor hand washing practice had a statistically significant association with detection of suspected diarrheagenic $E$. coli infection. Children from households that wash their hands before and after meals are $81 \%$ less likely to have DEC infection compared to children from households who don't wash their hands (AOR $=0.19,95 \% \mathrm{CI}=0.144$ $0.775, P$-value $=0.004)($ Table 3$)$.

From a total of 253 respondents, 158 (62.5\%) of them stated diarrhea as a common childhood illness in their area. $225(88.9 \%)$ respondents associated the sources of children's diarrheal infection with poor personal and environmental hygiene (Table 4).

The majority of respondents, 92.5\% $(n=234)$ and 78.3\% $(n=198)$ mentioned frequent diarrhea and abdominal pain as important and noticeable symptoms of childhood diarrhea, respectively. However, a few (3.6\%) participants were not aware of the signs and symptoms.

Regarding their practice, the majority of the caretakers went to health centers, and no one sought out traditional healers. 91.7\% $(n=232)$ participants went to health centers, $7.5 \%(n=19)$ went to hospitals, and $0.8 \%(n=2)$ went to private clinics for medical treatment. Any fluid intake, defined as taking of any fluid drinks in addition to oral rehydration solutions, was noted as a control mechanism in $89.3 \%(n=226)$ of respondents. Consequently, more than $90 \%$ of the caretakers used oral rehydration solution (ORS) as a treatment option (Table 5).

56.1\% $(n=142)$ and 9.1\% $(n=23)$ of caretakers used raw milk and raw meat, respectively. However, there was no statistically significant association detected 
Table 1 Distributions of socio-demographic characteristics of children and caretakers at the selected public health institutions in Addis Ababa, Ethiopia, 2015

\begin{tabular}{|c|c|c|c|c|}
\hline $\begin{array}{l}\text { Study } \\
\text { Subjects }\end{array}$ & Variable & Category & $\begin{array}{l}\text { Frequency, } \\
n=253\end{array}$ & Percent \\
\hline & Sex & Male & 115 & 45.5 \\
\hline & & Female & 138 & 54.5 \\
\hline \multirow[t]{9}{*}{ Children } & & $<1 \mathrm{yrs}$ & 32 & 12.6 \\
\hline & Age & $1-2$ yrs & 72 & 28.5 \\
\hline & & $2-3 y r s$ & 64 & 25.3 \\
\hline & & $>3 \mathrm{yrs}$ & 84 & 33.6 \\
\hline & Sex & Male & 33 & 13.0 \\
\hline & & Female & 220 & 87.0 \\
\hline & Age & $\leq 25 \mathrm{yrs}$ & 78 & 30.0 \\
\hline & & $26-40$ yrs & 167 & 66.0 \\
\hline & & $\geq 41 \mathrm{yrs}$ & 8 & 3.2 \\
\hline \multirow[t]{17}{*}{ Caretakers } & Marital Status & Single & 15 & 6.0 \\
\hline & & Married & 218 & 86.2 \\
\hline & & Divorced & 12 & 4.7 \\
\hline & & Other & 8 & 3.1 \\
\hline & $\begin{array}{l}\text { Educational } \\
\text { Status }\end{array}$ & Illiterate & 42 & 16.6 \\
\hline & & Primary & 164 & 64.9 \\
\hline & & Secondary & 33 & 13.0 \\
\hline & & $\begin{array}{l}\text { Higher } \\
\text { education }\end{array}$ & 14 & 5.5 \\
\hline & Occupation & Government & 25 & 9.9 \\
\hline & & Merchant & 63 & 24.9 \\
\hline & & Housewife & 135 & 53.4 \\
\hline & & Others & 30 & 11.8 \\
\hline & Monthly Income & $<500$ ETB & 119 & 47.0 \\
\hline & & 501-1000 ЕTB & 41 & 16.2 \\
\hline & & 1001-1500 ETB & 12 & 4.8 \\
\hline & & $>1500$ ETB & 5 & 2.0 \\
\hline & & Others & 76 & 30.0 \\
\hline
\end{tabular}

ETB Ethiopian Birr between users and non-users with culture positivity. Of all respondents, $97.2 \%(n=246)$ endorsed proper latrine usage. In general, children from caretakers with a low knowledge score were three times more likely to be exposed to $E$. coli infection than children from caretakers with a good knowledge score.

\section{Discussion}

The overall isolation prevalence rate of suspected diarrheagenic E. coli in diarrheic stool samples was found to be $24.1 \%$. This result was consistent with studies done in Ethio-Swedish Children's Hospital, Addis Ababa Ethiopia, and Tanzania, where $20.8 \%$ and $22.9 \%$ rates of E. coli isolates have been reported respectively $[10,15]$. However, our rates were lower compared to a $46.88 \%$ and $60.0 \%$ prevalence of suspected diarrheagenic E. coli from studies done in North West Italy and Nigeria, respectively $[16,17]$. In contrast, our participants had higher rates of suspected diarrheagenic E. coli when compared to a study in the US of both inpatients (4.7\%) and emergency room (10.0\%) subjects [18]. Put together, the differences noted in the various populations might be due to age, socio-economic factors, and the nature of the public water supply.

$83.6 \%$ of suspected diarrheagenic E. coli isolates were resistant to ampicillin (83.6\%) and augmentin (83.6\%). This in to contrast to other studies in other parts of Ethiopia, where ampicillin resistance was 93.70\% [19]. This might be due to the difference in study design, place, age and period. The high prevalence of resistance to these drugs could be explained by the longtime use of this antibiotic to treat enteric bacterial infection, thereby ensuring selection pressure and maintenance of this resistance. Studies done in Peru, Iran, Nigeria, and Tanzania also show that diarrheagenic E. coli exhibited high levels of antimicrobial drug resistance [20-23].

In this study, multidrug resistance to two or more antibiotics $(85.2 \%)$ was more commonly observed than resistance to a single drug (3.3\%). Despite the high proportion of antimicrobial resistance observed among suspected diarrheagenic $E$. coli isolates, these organisms remain highly susceptible to ciprofloxacin and ceftriaxone, which are now the drugs of choice in many areas. This finding is in agreement with other studies done in Nigeria and Tanzania [18, 21-24].

Table 2 Antimicrobial susceptibility patterns of E. coli isolates among children under five years of age at the selected public health institutions in Addis Ababa, Ethiopia, 2015

\begin{tabular}{|c|c|c|c|c|c|c|c|c|c|}
\hline \multirow[t]{2}{*}{ Enteropathogen (n) } & \multirow[t]{2}{*}{ Interpretation } & \multicolumn{8}{|c|}{ Antibiotics } \\
\hline & & Amp & Aug & SXT & C & CIP & Gen & $\mathrm{Na}$ & CRO \\
\hline \multirow[t]{3}{*}{ Suspected Diarrheagenic E. coli (61) } & $\mathrm{S}(\%)$ & 11.5 & 9.8 & 36.1 & 72.1 & 93.4 & 63.9 & 73.8 & 96.7 \\
\hline & I (\%) & 4.9 & 6.6 & 1.6 & 6.6 & 1.6 & 24.6 & 6.6 & 0 \\
\hline & $\mathrm{R}(\%)$ & 83.6 & 83.6 & 62.3 & 21.3 & 4.9 & 11.5 & 19.7 & 3.3 \\
\hline
\end{tabular}

"S sensitive, I intermediate, and R resistant, Amp Ampicillin, Aug Augmentin, SXT trimethoprim-sulfamethoxazole, C Chloramphenicol, NA Nalidixic Acid, CIP Ciprofloxacin, Gen Gentamicin, CRO Ceftriaxone, $n$ number 
Table 3 Associations of risk factor with culture positivity of E. coli at the selected public health institutions in Addis Ababa, Ethiopia, 2015

\begin{tabular}{|c|c|c|c|c|c|c|}
\hline \multirow[t]{2}{*}{ Variables } & \multicolumn{5}{|c|}{ Suspected Diarrheagenic E. coli } & \multirow[t]{2}{*}{ P-Value } \\
\hline & Negative, N (\%) & Positive, N (\%) & $\operatorname{COR}(\mathrm{Cl})$ & $P$-Value & $\mathrm{AOR}(\mathrm{Cl})$ & \\
\hline \multicolumn{7}{|l|}{ Marital Status } \\
\hline Never Married & 12(75.0) & $4(25.0)$ & 1 & 0.93 & & \\
\hline Ever Married & 180(75.9) & $57(24.1)$ & $0.95(0.29-3.1)$ & & & \\
\hline \multicolumn{7}{|l|}{ Educational status } \\
\hline Illiterate & $29(69.0)$ & 13(31.0) & $1.28(0.17-9.9)$ & 0.33 & & \\
\hline Primary school & 126(76.8) & $38(23.2)$ & $0.73(0.09-5.8)$ & 0.51 & & \\
\hline Secondary school & 26(78.8) & $7(21.2)$ & $1.06(0.15-7.8)$ & 0.40 & & \\
\hline Higher education & 11(78.6) & $3(21.4)$ & 1 & & & \\
\hline \multicolumn{7}{|l|}{ Occupation } \\
\hline Government & 19(76.0) & $6(24.0)$ & 1 & & & \\
\hline Merchant & 49(77.8) & 14(22.2) & $0.19((0.2-1.9)$ & 0.30 & & \\
\hline Housewife & $101(74.8)$ & $34(25.2)$ & $0.38(0.4-3.5)$ & 0.41 & & \\
\hline Others & $23(76.7)$ & $7(23.3)$ & $3.12(0.3-30.7)$ & 0.33 & & \\
\hline \multicolumn{7}{|l|}{ Monthly Income } \\
\hline$<500$ & $98(72.1)$ & $38(27.9)$ & $3.8(1.5-9.8)$ & $0.006^{*}$ & $0.12(-0.05-001)$ & 0.060 \\
\hline $501-1000$ & $37(69.8)$ & 16(30.2) & $6.5(1.9-21.8)$ & $0.003^{*}$ & $0.22(0.64-1.3)$. & 0.056 \\
\hline $1001-1500$ & $27(84.4)$ & $5(15.6)$ & $1.3(0.12-12.2)$ & 0.61 & $1.13(0.22-5.74)$ & 0.880 \\
\hline$>1501$ & 30(93.8) & $2(6.2)$ & 1 & & & \\
\hline \multicolumn{7}{|l|}{ Family previous diarrhea } \\
\hline Yes & $22(71.0)$ & $9(29.0)$ & $1.47(0.53-1.4)$ & 0.64 & & \\
\hline No & 170(76.6) & $52(23.4)$ & 1 & & & \\
\hline \multicolumn{7}{|l|}{ Attending day care } \\
\hline Yes & 73(79.3) & 19(20.7) & 1 & & & \\
\hline No & 119(73.9) & $42(26.1)$ & $1.3(0.7-2.4)$ & 0.35 & & \\
\hline \multicolumn{7}{|l|}{ Feeding practice } \\
\hline Exclusive breast milk & $35(89.7)$ & $4(10.3)$ & 1 & & & \\
\hline Breast milk \& solid food & $58(72.5)$ & $22(27.5)$ & $3.5(1.07-11.0)$ & 0.07 & & \\
\hline Solid food only & $95(73.6)$ & $34(26.4)$ & $3.5(1.1-11.2)$ & 0.08 & & \\
\hline Formula Milk & $4(80.0)$ & $1(20)$ & $2.6(0.23-34.4)$ & 0.28 & & \\
\hline \multicolumn{7}{|l|}{ Proper usage of latrine } \\
\hline Yes & 187(76.0) & $59(24.0)$ & 1 & & & \\
\hline No & $5(71.4$ & $2(28.6)$ & $0.7(0.05-11.6)$ & 0.83 & & \\
\hline \multicolumn{7}{|l|}{ Raw meat usage } \\
\hline Yes & $111(78.2)$ & $2(8.7)$ & $0.26(0.06-1.2)$ & 0.08 & & \\
\hline No & $81(73.0)$ & $59(25.7)$ & 1 & & & \\
\hline \multicolumn{7}{|c|}{ Hand washing before \& after meal } \\
\hline Yes & 190(77.2) & $56(22.8)$ & 1 & & & $0.004^{*}$ \\
\hline No & $2(28.6)$ & $5(71.4)$ & $0.12(0.02-0.6)$ & $0.03^{*}$ & & $0.2(0.2-8)$ \\
\hline \multicolumn{7}{|l|}{ Sources of water } \\
\hline Pipe & 188(76.1) & 59(23.9) & 1 & & & \\
\hline Other & $4(66.7)$ & 2(33.3) & $1.6(0.29-8.9)$ & 0.60 & & \\
\hline
\end{tabular}


Table 3 Associations of risk factor with culture positivity of E. coli at the selected public health institutions in Addis Ababa, Ethiopia, 2015 (Continued)

\begin{tabular}{|c|c|c|c|c|c|c|}
\hline \multirow[t]{2}{*}{ Variables } & \multicolumn{5}{|c|}{ Suspected Diarrheagenic E. coli } & \multirow[t]{2}{*}{$P$-Value } \\
\hline & Negative, N (\%) & Positive, N (\%) & COR (CI) & $P$-Value & $\mathrm{AOR}(\mathrm{Cl})$ & \\
\hline \multicolumn{7}{|l|}{ Knowledge } \\
\hline Good & 168(79.2) & $44(20.6)$ & 1 & & & \\
\hline Poor & $24(58.5)$ & $17(41.5)$ & $2.65(1.3-5.4)$ & $0.008^{*}$ & $2.70(1.33-5.5)$ & \\
\hline \multicolumn{7}{|l|}{ Attitude } \\
\hline Positive & $173(77.6)$ & $50(22.4)$ & 1 & & & \\
\hline Negative & $19(63.3)$ & $11(36.7)$ & $1.8(0.88-4.11)$ & 0.163 & & \\
\hline \multicolumn{7}{|l|}{ Practice } \\
\hline Good & $181(76.1)$ & $57(23.9)$ & 1 & & & \\
\hline Poor & $11(73.3)$ & $4(26.7)$ & $1.4(0.4-4.7)$ & 0.582 & & \\
\hline
\end{tabular}

*Statistically significant, $\mathrm{Cl}$ 95\% confidence interval, COR crude odds ratio, AOR adjusted odds ratio

Adjusted OR (adjusted odds ratio from multivariable logistic regression model) $=$ when the effect of one factor on E. coli prevalence is evaluated the analysis was adjusted for other remaining factors listed in the table

A few of the caretakers had completed a higher level of education, and their children had a lower frequency of suspected diarrheagenic E. coli isolation. This is similar to a study showing a $54 \%$ risk reduction for severe disease among mothers with 7 or more years of education [25-27].

The features of acute diarrhea vary from place to place depending on local meteorology, geography, and socioeconomic variables [16]. However, common presenting features of suspected diarrheagenic E. coli include diarrhea that was watery or bloody, with or without mucus, fever, vomiting and abdominal pains. Similarly, in our cohort, the most useful signs and symptoms for the diagnosis of E. coli were the complaints of watery diarrhea, as reported in other studies [19].

Drinking of unsafe water and contaminated foods are often considered to increase exposure to enteropathogens and have been associated with increased rates of acute diarrhea [3]. This finding is contrary to a study in India that shows teething (64.3\%), evil eye $(46 \%)$, contact with another case $(36.6 \%)$, worm infestation (22.6\%), dirty water (15.3\%), and dirty environment (6\%) as causes [27].

Of all, $93.7 \%$ of the caretakers agreed that personal hygiene is an effective means to prevent childhood diarrhea and $88.5 \%$ mentioned breast milk. Moreover, during episodes of diarrheal illnesses, 92.5\% $(n=234)$ of the mothers preferred breast milk. This attitude and practice is consistent with findings in Gondar, Ethiopia, that showed breast-feeding is protective factor [28]. This is also supported by other findings; breast-feeding especially if it is the only source of nutrition, has been shown to protect children against the development of diarrhea in Africa, as elsewhere in the developing world [3].
The majority of the caretakers went to health centers and no one consulted traditional healers. This is in agreement with studies done in other country [26]. 89\% of mothers $(n=226)$ preferred fluids in contrast with other studies in Nepal where $15.7 \%$ preferred fluids [29]. Oral rehydration therapy was used as a treatment solutions for majority (90.9\%) of caretakers, in contrast to other findings in India, where only $13(4.3 \%)$ preferred ORS [27]. This difference might be due to the educational status of the participant, as it is shown in the current study only $42(16.6 \%)$ of the study subjects were illiterate as compared to $70 \%$ the previous study.

\section{Conclusion}

We detected a high frequency of multi drug resistance suspected diarrheagenic $E$. coli in isolated bacteria in children under 5 with acute diarrheal illness. The majority of the participants' caregivers had a good level of awareness when asked about the potential causes of diarrhea (e.g. which is mostly due to poor sanitation). Additionally, there was a statistically significant association detected between low levels of knowledge and suspected diarrheagenic E. coli culture positivity. This indicated that those respondents, who have low awareness about source, cause and symptoms of the disease were more likely to acquire suspected diarrheagenic E. coli infections. Thus, there is a need for further education in the community about how diarrhea illnesses are transmitted. Additionally, while our data suggest ciprofloxacin or ceftriaxone are good choices for empiric therapy of suspected diarrheagenic E. coli, antimicrobial resistance patterns can evolve. Hence, there is a still need for continuous surveillance of the prevalence and antibiotic susceptibility pattern of diarrheal bacterial isolates in hospitals and in the community. 
Table 4 Distributions of respondents according to knowledge and attitude towards the symptom and cause of childhood diarrhea at the selected public health institutions in Addis Ababa, Ethiopia, 2015

\begin{tabular}{|c|c|c|}
\hline $\begin{array}{l}\text { Cause, Symptoms and } \\
\text { prevention of diarrhea }\end{array}$ & Variable & $\overline{\text { Frequency }(\%)}$ \\
\hline \multirow{8}{*}{$\begin{array}{l}\text { Cause of childhood diarrhea } \\
\text { mentioned }\end{array}$} & Poor personal hygiene & 225 \\
\hline & Contaminated food/water & $211(83.4)$ \\
\hline & Microorganisms & $140(55.3)$ \\
\hline & Inadequate breast milk & $137(54.1)$ \\
\hline & Teething & $116(45.8)$ \\
\hline & Evil eye & $40(15.8)$ \\
\hline & House flies & $109(48.1)$ \\
\hline & Do not know & $6(2.4)$ \\
\hline \multirow[t]{6}{*}{$\begin{array}{l}\text { Sign/symptoms of } \\
\text { childhood diarrhea }\end{array}$} & $\begin{array}{l}3-4 \text { times loose stool per } \\
\text { day }\end{array}$ & $234(92.5)$ \\
\hline & Abdominal pain & $198(78.3)$ \\
\hline & Fever & $165(65.2)$ \\
\hline & Vomiting & $140(55.3)$ \\
\hline & Tenesmus & $134(53.1)$ \\
\hline & Do not known & $9(3.6)$ \\
\hline \multirow[t]{3}{*}{$\begin{array}{l}\text { Cause to worsens childhood } \\
\text { diarrhea }\end{array}$} & $\begin{array}{l}\text { Contact with infected } \\
\text { people }\end{array}$ & $228(90.1)$ \\
\hline & High fluid intake & $122(48.2)$ \\
\hline & Formula milk & $120(47.4)$ \\
\hline \multirow[t]{8}{*}{ Preventive methods } & Oral rehydration solutions & $240(94.9)$ \\
\hline & Personal hygiene & $237(93.7)$ \\
\hline & Breast milk & $224(88.1)$ \\
\hline & Clean water intake & $162(64.0)$ \\
\hline & Anti-diarrheal treatment & $123(48.6)$ \\
\hline & Antibiotics & $53(20.9)$ \\
\hline & Traditional medicine & $22(8.7)$ \\
\hline & Do not know & $12(4.7)$ \\
\hline
\end{tabular}

Note: Percentages do not add up to 100 because of multiple responses

Table 5 Practices of respondents towards childhood diarrhea prevention and control at the selected public health institutions in Addis Ababa, Ethiopia, 2015

\begin{tabular}{ll}
\hline Variables & Frequency (\%) \\
\hline Exclusive breast feeding & $234(92.5)$ \\
Oral rehydration solutions & $230(90.9)$ \\
Any fluid intake in addition to ORS & $226(89.3)$ \\
Anti-diarrheal treatment & $31(12.3)$ \\
Antibiotics treatment & $13(5.1)$ \\
Traditional medicines & $1(0.4)$ \\
Do not use & $2(0.8)$
\end{tabular}

Note: Percentages do not add up to 100 because of multiple responses
Combined efforts should be also implemented to reduce childhood death rates by improving the knowledge, attitude, and practices level aimed at improving environmental (i.e. water sources) and personal hygiene (i.e. hand washing). Therefore, intensive health education is a public health priority that, together with more judicious use of antimicrobials, could preserve antimicrobial efficacy and substantially reduce diarrheal illness.

\section{Abbreviations \\ Cl: Confidence Interval; CLSI: Clinical Laboratory Standard Institutes; DCA: Deoxycholate citrate agar; DEC: Diarrheagenic Escherichia coli; DRERC: Department Research and Ethical Review Committee; $E$. coli: Escherichia coli; ETB: Ethiopian Birr; KAPs: Knowledge, attitude, and practices; MAC: MacConkey agar; SPHMMC: St. Paul's Hospital Millennium Medical College; SSA: Salmonella Shigella agar; WHO: World Health Organization.}

\section{Acknowledgements}

The authors would like to thank School of Medical Laboratory Technology, Addis Ababa University and staff members of St. Paul's Hospital Millennium Medical College administration and laboratory staff facilitating the overall the research work. We would also like to extend our profound gratitude to the study subjects without their consent and the provision of the demanded information this research work would not have been real. Last but not least we would like to acknowledge Amy Vercler, Admin Assistant of the SPHMMC and Oludare A. Odumade, MD/PhD, Global Health Pediatric Researcher / Intermediate Care Program Hospitalist, Division of Medical Critical Care / Boston Children's Hospital / Harvard Medical School, United States, who enriched language edition this manuscripts.

\section{Funding}

This study was funded by Addis Ababa University, Ethiopia. Funder has role in the study design and data collection but has no any role in writing the manuscript.

\section{Availability of data and materials}

The data that support the findings of this study will be available from the corresponding author upon reasonable request in the form of statistical package for social sciences (SPSS).

\section{Authors' contribution}

YM Principal investigator of the study, study design, data collection, laboratory work, and data analysis; AG \& KD Study design and data analysis and supervision of the work; AG drafting the manuscript and revising it critically for important intellectual content. All authors contributed to the write up. All authors commented and approved the final manuscript.

\section{Ethics approval and consent to participate}

Ethical approval was obtained from the Department of Medical Laboratory Science, College of Health Science, Addis Ababa University Research and Ethical Review Committee. Informed written permission was obtained from St. Paul's Millennium Medical College Institutional Review Board (IRB) and submitted to the head of the laboratory department. Any data generated from the specimens protected the patent privacy, confidentiality and anonymity.

\section{Consent for publication}

Written informed consent was taken from study participants for publication explaining: the objective and benefit of the finding of the study and their personal identifiers was not attached.

\section{Competing interests}

The authors declare that they have no competing interests.

\section{Publisher's Note}

Springer Nature remains neutral with regard to jurisdictional claims in published maps and institutional affiliations. 


\section{Author details}

'Department of Microbiology, St. Paul's Hospital Millennium Medical College, P.O.Box 1271, Addis Ababa, Ethiopia. ${ }^{2}$ Department of Microbiology, School of Medical Laboratory Sciences, College of Health Science, Addis Ababa University, Addis Ababa, Ethiopia.

Received: 23 April 2018 Accepted: 4 September 2018

Published online: 12 September 2018

\section{References}

1. Ina' c MM, Euse' b VM, Joaquim $R$, et al. Etiology of diarrhea in children younger than 5 years of age admitted in a rural hospital of southern Mozambique. Am J Trop Med Hyg. 2007;76(3):522-7.

2. Kosek M, Bern C, Guerrant R. The global burden of diarrheal disease, as estimated from studies published between 1992 and 2000. Bulle World Health Organ. 2003;81:197-204

3. Bryce J, Boschi-pinto C, Shibuya K, Black RE. WHO Child Health Epidemiology Reference Group WHO estimates of the causes of death in children. Lancet. 2005;365:1147-52.

4. Tiruneh M. Serodiversity and antimicrobial resistance pattern of Shigella isolates at Gondar University teaching hospital, Northwest Ethiopia. Jpn J Infect Dis. 2009:62:93-7.

5. O'Ryan M, Prado V, Pickering LK. A millennium update on pediatric diarrheal illness in the developing world. Semin Pediatr Infect Dis. 2005;16:125-36.

6. Viswanathan VK, Hodges $K$, Hecht G. enteric infection meets intestinal function. Rev Microbiol. 2009:7:110-9.

7. World Health Organization (WHO). Global strategy for containment of antimicrobial resistance. WHO Geneva, 2001; http://www.who.int/drugresistance/en. (Accessed 22 Apr 2012).

8. Isenbarger DW, Hoge CW, Srijan A, Pitarangsi C, Vithayasai N, Bodhidatta L, et al. Comparative antibiotic resistance of diarrheal pathogens from Vietnam and Thailand, 1996-1999. Emerg Infect Dis. 2002;8:175-80.

9. Vu Nguyen T, Van Le P, Huy Le C, Weintraub A. Antibiotic resistance in Diarrheagenic Escherichia coli and Shigella strains isolated from children in Hanoi, Vietnam. Antimicrob Agents Chemother 2005:49(2):816-9.

10. Asrat D. Screening for enteropathogenic Escherichia coli (EPEC) in paediatric patients with diarrhoea and controls using pooled antisera. Ethiop Med J. 2001;39(1):23-8

11. Mamuye Y, Metaferia G, Birhanu A, Desta K, Fantaw S. Isolation and antibiotic susceptibility patterns of Shigella and Salmonella among under 5 children with acute Diarrhoea. Clinical Microbiology. 2015;4:1.

12. Chees Brough M. District laboratory practice in tropical countries. ECBS edition .Cambridge University Press, 2002; (2):97-182.

13. Feng, P., Weagant, S. D., and Jinneman, K. (2015). Bacteriological Analytical Manual Chapter 4a Diarrheagenic Escherichia coli. Available at: http://www. fda.gov/Food/FoodScienceResearch/LaboratoryMethods/ucm070080.htm.

14. Clinical and Laboratory Standards Institute (CLSI). Performance Standards for Antimicrobial Disk Susceptibility Tests; Approved Standard-Ninth Edition. USA: Pennsylvania: CLSI. Pennsylvania 19087-1898; 2010.

15. Moyo SJ, Maselle SY, Matee MI, Langeland N, Mylvaganam H. Identification of diarrheagenic Escherichia coli isolated from infants and children in dares salaam, Tanzania. BMC Infect Dis. 2007;7:92.

16. Amisano G, Fornasero S, Migliaretti G, Caramello S, Tarasco V. \&Savino F. Diarrheagenic Escherichia coli in acute gastroenteritis in infants in northWest Italy. New Microbiol. 2011;34:45-51.

17. Akinjogunla OJ, Eghafona NO, Ekoi OH. Diarrheagenic Escherichia coli (DEC): prevalence among in and ambulatory patients and susceptibility to antimicrobial chemotherapeutic agents. J Bacteriol Res. 2009;1(3):34-8.

18. Cohen MB, Nataro JP, Bernstein DI, Hawkins J, Roberts N, Staat MA. Prevalence of diarrheagenic Escherichia coli in acute childhood enteritis: a prospective controlled study. J Pediatr. 2005;146(1):54-61.

19. Agumas LG, Belachew GG, Tekle EL, Mekonnen A. Multiple drug resistance patterns of fecal isolates of enteric bacterial species in Tigray, Northern Ethiopia: A 10-year retrospective analysis. J Pharm Res. 2011;10(4):3259-63.

20. Nataro JP, Kaper JB. Diarrheagenic Escherichia coli. Clin Microbiol Rev. 1998; 11:142-201.

21. Ochoa TJ, Ruiz J, Molina M, Del Valle $\sqcup$, Vargas M, Gil Al. High frequency of antimicrobial drug resistance of Diarrheagenic Escherichia coli in infants in Peru. Am. J. Trop. Med. Hyg. 2009;81(2):296-301.

22. Vila J, Vargas M, Casals C, Urassa H, Mshinda H, Schellemberg D, et al. antimicrobial resistance of Diarrheagenic Escherichia coli isolated from children under the age of 5 years from Ifakara, Tanzania. Antimicrobial Agents Chemother. 1999:43(12):3022-4.

23. Jafari F, Hamidian M, Rezadehbashi M, Doyle M, Salmanzadeh-ahrab S, Derakhshan F, et al. Prevalence and antimicrobial resistance of diarrheagenic Escherichia coli and Shigella species associated with acute diarrhea in Tehran, Iran. Can J Infect Dis Med Microbiol. 2009;20(3):56-62.

24. Okeke IN, Aboderin OA, Byarugaba DK, Ojo KK, Opintan JA. growing problem of multidrug- resistant enteric pathogens in Africa. Emerg Infect. 2007;13(11):1640-6

25. Carattoli A. Resistance plasmid families in Entrobacteriaceae. Antimicrobial Agents and Chemoter. 2009:53(6):2227-38.

26. Labay EM, Bhuiyan SU, Hongkrailert N. Risk factors relating to the diarrheal disease occurrence among under 5 children at Samut Sakhon Province. Thailand J Pub Heal and Dev. 2007;5(3):63-74.

27. Kapoor P, Raiput VJ. Knowledge, attitude and practice in diarrhea. Indian Pediatr. 1993;33:319-20.

28. Rishi PM, Amsalu F, Lawrence HM, Sisay Y, Bradley RS. Risk factors and case Management of Acute Diarrhea in North Gondar zone, Ethiopia. J Health Popul Nutr. 2010;28(3):253-63.

29. Rehan HS, Gautam K, Gurung K. Mothers needs to know more regarding management of childhood acute diarrhea. Indian. J Prev Soc Med 2003:34(1 \& 2):41-5.
Ready to submit your research? Choose BMC and benefit from:

- fast, convenient online submission

- thorough peer review by experienced researchers in your field

- rapid publication on acceptance

- support for research data, including large and complex data types

- gold Open Access which fosters wider collaboration and increased citations

- maximum visibility for your research: over $100 \mathrm{M}$ website views per year

At $\mathrm{BMC}$, research is always in progress.

Learn more biomedcentral.com/submissions 